\title{
Making Mountains, on Earth and Beyond
}

Nigel Harris ${ }^{1}$, Professor Emeritus, Open University, Milton Keynes MK7 6AA

\begin{abstract}
Many of Earth's mountains are formed in orogenic belts aligned along plate margins. Their altitudes (reaching $>8,000 \mathrm{~m}$ above sea level in the Himalayas) are the result of the balance between tectonic forces causing their uplift and erosive processes causing their destruction. The tectonic forces result, in part, from isostacy which is determined by the plasticity of the asthenosphere, but gravity studies across the Himalayas suggest that the highest parts of the range require an additional force to support their altitude which is provided by the flexural rigidity of the lithosphere. This is well demonstrated by the 2015 earthquake in Nepal where radar images before and after the $7.8 \mathrm{M}$ event record a decrease in altitude of the High Himalayas as a consequence of weakening and rupture of the lithosphere by the earthquake.
\end{abstract}

Radar images of Venus, a planet of similar size to the Earth, provide evidence of $10,000 \mathrm{~m}$ mountain ranges, also similar to Earth. However, venusian mountains do no define the sinuous forms of Earth's great ranges. This demonstrates that mountains of Himalayan altitudes can form in the absence of plate tectonics. On Venus, persistent compressive forces acting on hot lithosphere has led to significant horizontal shortening by ductile mechanisms to form fold-and-thrust belts within thickened crust around the margins of crustal plateaux, possibly analogous to tectonics on the early Earth. Maximum altitudes are unlikely to be climate limited (surface erosion on Venus is low due to the absence of water in the atmosphere) and so must be limited by rock strength. The similarity in maximum altitudes of mountains on Earth and Venus suggests that rock strength is probably the dominant factor in determining the maximum height of mountains on both planets.

Mountains are also formed from volcanic eruptions. Comparisons are drawn between Earth's Mauna Kea (10,000 m from it's ocean floor base) and the martian Olympus Mons $(>21,000 \mathrm{~m})$. The staggering dimensions of the latter volcano requires the

${ }^{1}$ Address for correspondence: n.b.w.harris@open.ac.uk. This submission is a preprint. 
absence of plate tectonics which allows a hot spot to generate magmatism at the same point on the surface for hundreds of millions of years. However the flexural rigidity of the lithosphere must also be sufficient to support the massive volcanic edifice and this is found to be significantly higher on Mars than on the Earth's ocean floor, due in part to the greater thickness of the martian crust and the absence of a low-viscosity asthenosphere. The smaller planetary mass of Mars is also a factor in supporting a volcano of such dimensions.

Extra-terrestrial examples of mountain building are also taken from Saturn's largest moon, Titan and from the dwarf planet Pluto. Mountains ranges on Titan reach altitudes of $\sim 3,300 \mathrm{~m}$, much lower than maximum altitudes on Earth. The mountains are formed in an icy rigid outer layer (surface temperatures are $-180^{\circ} \mathrm{C}$ ) which overlies a water-ammonia sub-surface ocean. On Pluto, with a mass one tenth that of Titan, mountains reach altitudes of $\sim 6,200 \mathrm{~m}$. In both cases the low mechanical strength of the sub-surface layer prevents mountains approaching the much greater altitudes of terrestrial mountain ranges and confirms the paramount importance of material strength in determining the heights that mountains can achieve.

"We shall not cease from exploration, and the end of all our exploring will be to arrive where we started and know the place for the first time” T.S. Eliot

\section{Introduction}

This article seeks to review the processes by which mountains can evolve using examples in the inner and outer solar system. It uses extra-terrestrial examples to identify the forces that fashion Earth's highest mountains and addresses the question 'why are Earth's mountains not higher than they are?'

\section{Tectonic mountain building on Earth}

The highest point above on Earth is Mount Everest which reaches a height of 8,848 m above sealevel (Fig. 1). We know from the discovery of crinoids (marine fossils) on its summit that Everest has been pushed up from the sea floor, a distance of nearly 9 
km (Odell 1967). Everest is part of the vast Himalayan mountain chain over $2000 \mathrm{~km}$ long which stretch from Pakistan to N.W. India, Nepal (where they mark the border with Tibet), Sikkim, Bhutan and into eastern Tibet. These mountains result from the collision between two continental tectonic plates, India and Eurasia, about $50 \mathrm{Ma}$ ago. This massive collision continues today as the plates continue to converge due in part to deforming the crust beneath the Himalaya and Tibet. During the deformation both the continental crust and the entire lithosphere are substasntially thickened. Uplift follows such thickening through a process called isostacy.

To understand isostacy it is useful to consider a series of blocks floating on water (Fig. 2). The more elongated is the block the higher the top of the block will rise above the water's surface. The blocks represent the Himalayan lithosphere, being of lower density than the water (asthenosphere). The tallest blocks have deep lithospheric roots. The base of the block represents the isostatic compensation depth which is the interface between the bottom of the lithosphere and the top of the asthenosphere. In reality the asthenosphere is not a liquid but a solid that can flow by plastic deformation. Reaching isostatic equilibrium is not an instantaneous process and the time the mountains take to reach their equilibrium altitudes depends on the relative rates of deformation, causing thickening, and of plastic flow in the asthenosphere.

Most mountain ranges are not in perfect isostatic equilibrium. To test for isostatic equilibrium, geophysicists can calculate the gravitational anomaly for theoretical Airy isostatic equilibrium at any point across the orogen. In the case of the highest Himalayan mountains the measured gravity anomalies are systematically higher than these equilibrium values (Cattin et al. 2001) a situation described as 'under compensation'. Put another way, the topography is not fully supported by the crustal root. This is important because it implies there is another force supporting the mountains. Incidentally the foreland basin into which the eroded products of the Himalaya are deposited by the Ganges and Brahmaputra rivers is 'over compensated' meaning that the actual crustal root is greater than is predicted by isostatic equilibrium. This is because the rate of deposition of eroded material from the Himalayas (adding mass to the lithosphere at the suface) is faster than flow in the asthenosphere can restore the equilibrium position at that point. 
What is this second force supporting the high mountains? A clue to this question is offered by studies of ground movement following the 7.8 M Gorkha (Nepal) earthquake in 2015. Radar mapping revealed that whilst the Kathmandu valley had risen in altitude, the altitudes of the High Himalaya to the north had actually decreased in height by about $0.6 \mathrm{~m}$ (Diao et al. 2015). The earthquake was the energy released by fault movement which weakened the lithosphere and so decreased the altitude of mountains that could be supported. The strength of the lithosphere, known as flexural rigidity, is a second key factor in supporting mountains. This rigidity is a function of rock composition, the strain rate and the geotherm.

Any geologist will know that as well as tectonics pushing rocks upwards, there is a potential for surface erosion to reduce altitudes at the surface. There is a balance of upward forces (lithospheric strength and isostacy) pushing rocks upwards (at about 7 $\mathrm{mm} / \mathrm{yr}$ in the central Himalaya), surface denudation (erosion) lowering their elevations (at about $3 \mathrm{~mm} / \mathrm{yr}$ ) resulting in a net increase in altitude of about $4 \mathrm{~mm} / \mathrm{yr}$. There is active debate about whether the limiting factor on mountain elevations is the rate of erosion or the rate of tectonic uplift.

The idea that mountains are carved downwards by their weathering is an old one; in the $19^{\text {th }}$ century a U.S. geomorphologist wrote "the mountains were not thrust up as peaks, but a great block was slowly lifted and from this the mountains were carved by the clouds - patient artists who take what time might be necessary for their work" (Powell 1875). Much more recently it has been noted that most peaks on Earth are about $1500 \mathrm{~m}$ above the snowline and it was concluded that the difference in heights of mountain ranges reflect variations in climate rather than tectonic forces (Egholm et al. 2009). To test what is the dominant factor determining mountain elevations it would be useful to find another planet, of similar size to Earth, where tectonics was active but which lacked vigorous erosion.

\section{The mountains of Venus}


Venus is one of our neighbouring planets with a mass $80 \%$ that of the Earth and made up largely of silicate minerals, as is Earth. The atmosphere though differs strongly from that on Earth, being composed of $\mathrm{CO}_{2}$ and sulphuric acid and lacking $\mathrm{H}_{2} \mathrm{O}$. The highest mountain range on Venus is Maxwell Montes, rising to the peak of Skadi Mons at 10,700 m (Fig. 3). These altitudes are similar to maximum elevations on Earth, but what differs sharply from the Earth is the distribution of the mountains which tend to develop sub-parallel ridges around high plateau margins (Fig. 3) rather than define linear (Andean) or arc-like (Himalayan) arrays, as on Earth where the major mountain belts have formed along active, or former, plate margins. Seismic studies suggest the crust beneath Maxwell Montes has thickened from $30 \mathrm{~km}$ beneath the plateaux to $50 \mathrm{~km}$ beneath the mountains, so topography appears to be supported by a crustal root (Anderson and Smrekar 2006).

Venus is much hotter than Earth - average surface temperatures are $460^{\circ} \mathrm{C}$ compared to $14^{\circ} \mathrm{C}$ on Earth. Moreover, the lack of plate tectonics on Venus means that it lacks mid-ocean ridges, features that allow a high proportion of the internal heat loss on Earth. Consequently the temperature-depth gradient on Venus (the equivalent of the geothermal gradient on Earth) will be much steeper, favouring ductile deformation and the development of mountainous fold-and-thrust belts.

Comparisons between venusian and terrestrial mountain belts suggest that similar tectonic processes of compression and deformation, with crustal thickening, are at work, albeit Venus offers a one-plate environment. The absence of $\mathrm{H}_{2} \mathrm{O}$ in the venusian atmosphere suggests that weathering will be a minor process compared to Earth; indeed the principal causes of erosion of terrestrial rocks, such as glaciers or running water, diurnal and seasonal temperature changes, and aeolian abrasion, are all absent on Venus. The first-order conclusion from this simple comparison is that for silicate planets of mass similar to Earth, tectonics rather than surface erosion largely determines the maximum elevations of mountains.

\section{Volcano building on Mars and on Earth}


Tectonics provides only one way of constructing mountains. Large mountains can result from repeated volcanic eruptions which, over time, build up a large carapace typical of most shield volcanoes. Indeed it can be argued that Mauna Kea, one of five volcanoes that make up the Pacific island of Hawai'i, is the highest mountain on Earth. Although 4,207 $\mathrm{m}$ above sea level, measured from the sea floor from where the slopes originate, it is $10,200 \mathrm{~m}$. Such volcanoes generally grow from seamount summit eruptions which successively increase the height and width of the volcano; the weight of the growing volcanic pile provides an increasing downward force which is resisted by the flexural rigidity of the supporting lithosphere until the point at which the structure starts to subside.

The largest mountain in the solar system has such an origin, and is found on our other planetary neighbour, Mars. Olympus Mons rises 21,229 $\mathrm{m}$ above the martian plains and its base covers the area of France (Fig. 4). How is such an enormous structure possible? Is its existence a function of magma supply or to the strength of the lithosphere?

Olympus Mons eruptions occurred from about 3,670 Ma to 2,540 Ma. In comparison eruptions on Hawai'i date back only about $0.7 \mathrm{Ma}$. The calculated eruption rates are similar for the two volcanoes, about $0.01 \mathrm{~km}^{3} / \mathrm{yr}$ (Isherwood et al. 2013). However a key difference can be seen in the tectonic environment of the two volcanoes. Hawai'i is the prime example of an oceanic hot spot. As the Pacific plate migrates over the hot spot, a chain of islands has formed, tracing the direction of the moving plate (Fig. 5). In contrast, Mars has no plate tectonics and so the hot spot beneath Mons Olympus has persisted to erupt through the same lithospheric target for the lifetime of the thermal anomaly, in this case over 1,000 Ma. So it is not unreasonable to propose that the absence of plate tectonics is a necessary, but not sufficient, condition for the formation of a volcano of the dimensions of Olympus Mons.

A volcano can only increase in altitude if the rocks beneath it are sufficiently strong to support it. Around the base on Mons Olympus a flexural moat can be seen which is indicative that the great weight of the volcano is close to the limit that can be supported on Mars (Fig. 4). The seismic evidence from Mars suggests that the rocks are indeed stronger than beneath Hawai' $i$, whether measured in terms of a greater 
crustal thickness $(140 \mathrm{~km}$ versus $<20 \mathrm{~km})$, flexural rigidity $\left(1 \times 10^{32} \mathrm{~N}\right.$ m versus $1 \times 10^{23}$ $\mathrm{N} \mathrm{m})$ or effective elastic thickness $(>70 \mathrm{~km}$ versus $<40 \mathrm{~km})$ (McKenzie et al. 2002). It seems that both the lack of plate tectonics on Mars and the strength of its rocks contributed to the dimensions of Mons Olympus. A third factor has also played a role. The gravitational force acting on the mountain depends not only on the mass of the mountain but also on the mass of the planet. With the mass of Mars about a tenth that of Earth the weight of the volcano on the supporting rocks would have been considerably less than for a mountain of equal dimensions on Earth.

\section{Vesta: mountains from impact}

Beyond the orbit of Mars lies the asteroid belt. One of the largest of these asteroids, Vesta, provides evidence of mountain formation in the absence of either tectonics or magmatism. The lower hemisphere of Vesta was struck by a large impactor about $1500 \mathrm{Ma}$ ago (Schenk et al. 2012). With its mass being only $5 \times 10^{-3}$ percent of Earth's mass the result of this impact effectively rearranged the topography of half the asteroid in forming an impact crater over $500 \mathrm{~km}$ across, termed Rheasilvia (Fig. 6). Large impacts cause the rocks involved to behave like fluids causing not only craters as the impacted rocks rocks flow outwards but also central peaks within the craters as the displaced rocks rebound. In this case the crater reached depths of $13 \mathrm{~km}$ below the pre-impact surface and the central peak rose $22.5 \mathrm{~km}$ from the crater floor. Although representing some of the most formidable topography in the solar system the height of this peak rises a mere $9.5 \mathrm{~km}$ above the pre-impact surface. A peak of Himalayan dimensions indeed but given the low mass of Vesta compared to Earth it is not one that would challenge the strength of the supporting rocks beneath it.

\section{The mountains of Titan}

Beyond the asteroid belt lie the gas planets of Jupiter, Saturn, Uranus and Neptune. Several of their moons are known to have mountain belts, and some of the best documented are on Titan, the largest moon of Saturn. 
Titan's surface shows abundant evidence for tectonic activity. The rigid outer shell is a $200 \mathrm{~km}$ thick layer of water ice on the surface of which have formed independent mountains over $1400 \mathrm{~m}$ high and cryovolcanic calderas up to $1700 \mathrm{~m}$ deep (Kelley et al. 2018). The highest mountain range is Mithrim Montes which forms three parallel ridges reaching elevations of 3,337 m (Fig. 7), located near to Titan's equator. The driving force behind this tectonism is likely to be some combination of rotation from the spin of the moon, tidal deformation from the gravitational pull of Saturn, and contractural deformation as the moon looses internal heat. Perhaps the key question here is why are the mountains on Titan no higher than some modest mountain ranges on Earth, like the Pyrenees. Titan is much smaller than the Earth (0.02 of Earth's mass) and the density of the icy rigid layer forming the mountains is much less than for the rocks of Earth's mountains so surely higher mountains on Titan might be possible?

The answer probably lies in the strength of the materials that makes up Titan's outer layers. Not only is the rigid outer shell made up of ice, rather than silicate rock (which has characterised all the examples of mountains considered so far), but the subsurface shell is an ocean of water-ammonia. It is highly likely that such a weak material as liquid water would be unable to sustain mountains of any great height regardless of the tectonic activity within the outer rigid shell. One way to test this hypothesis is to consider a second example of a planet or moon with a liquid subsurface shell.

\section{The mountains of Pluto}

Pluto is a dwarf planet that lies in the Kuiper belt outside the orbit of the outermost gas planet, Neptune. It shares with Titan a water ice crust and a liquid water subsurface shell. It also shares a variety of mountain ranges, the highest being Tenzing Montes, rising to 6,200 m (Fig. 8) (Schenk et al. 2018). Little more is known about these distant hills except to note that they are almost double the altitude of Titan's highest peaks even though both share a weak inner shell made predominantly of water. Perhaps this difference is related to their relative masses, Titan being ten times the mass of Pluto. 


\section{Conclusions}

Looking beyond planet Earth can be revealing in terms of the physical processes that operate on a planetary scale (Fig. 9). The mountains of Venus tell us that mountains on a Himalayan scale can grow in the absence of plate tectonics, and that surface erosion is not required to limit their elevations from rising yet higher. From Mars we learn that sustained focussed magmatism, in the absence of plate tectonics, is one condition required to form massive volcanoes nearly three times the height of Everest, but also rock strength must be sufficient to support the volcano. Mars provides rock strength at depth in lacking a plastic asthenosphere that provides the isostatic compensation depth on Earth. The outer solar system provides evidence of subHimalayan scale mountain ranges on both Titan and Pluto, in both cases being supported by a weak sub-surface shell. In all examples, the heights that mountains can achieve are closely related to the strength of the materials that support them.

\section{Acknowledgements}

This presentation was the outcome of a question put to me by John Zarnecki (Professor Emeritus, Open University) following my valedictory address in January 2019. He asked if I had ever considered the formation of mountains on planetary bodies beyond Earth. I had not, so this is a small step in rectifying that omission. 


\section{References}

Anderson, F.S. and Smrekar, S.E., 2006. Global mapping of crustal and lithospheric thickness on Venus. Journal of Geophysical Research: Planets, 111(E8).

Cattin, R., Martelet, G., Henry, P., Avouac, J.P., Diament, M. and Shakya, T.R., 2001. Gravity anomalies, crustal structure and thermo-mechanical support of the Himalaya of Central Nepal. Geophysical Journal International, 147(2), pp.381-392.

Diao, F., Walter, T.R., Motagh, M., Prats-Iraola, P., Wang, R. and Samsonov, S.V., 2015. The 2015 Gorkha earthquake investigated from radar satellites: Slip and stress modeling along the MHT. Frontiers in Earth Science, 3, p.65.

Egholm, D.L., Nielsen, S.B., Pedersen, V.K. and Lesemann, J.E., 2009. Glacial effects limiting mountain height. Nature, 460(7257), p.884.

Isherwood, R.J., Jozwiak, L.M., Jansen, J.C. and Andrews-Hanna, J.C., 2013. The volcanic history of Olympus Mons from paleo-topography and flexural modeling. Earth and Planetary Science Letters, 363, pp.88-96.

Kelley, L., What Has Cassini-Huygens Discovered on Titan? Updated on November 15, 2018. https://owlcation.com/stem/Huygens-Mission-on-Titan.

McKenzie, D., Barnett, D.N. and Yuan, D.N., 2002. The relationship between Martian gravity and topography. Earth and Planetary Science Letters, 195(1-2), pp.116.

Odell, N.E., 1967. The highest fossils in the world. Geological Magazine, 104(1), pp.73-74.

Powell, J.W. (1875) 'Physical features of the Colorado Valley', The Popular Science Monthly, vol. 7, pp. 385-399. 
Schenk, P., O’Brien, D.P., Marchi, S., Gaskell, R., Preusker, F., Roatsch, T., Jaumann, R., Buczkowski, D., McCord, T., McSween, H.Y. and Williams, D., 2012.

The geologically recent giant impact basins at Vesta's south pole. Science, 336(6082), pp.694-697.

Schenk, P.M., Beyer, R.A., McKinnon, W.B., Moore, J.M., Spencer, J.R., White, O.L., Singer, K., Nimmo, F., Thomason, C., Lauer, T.R. and Robbins, S., 2018. Basins, fractures and volcanoes: Global cartography and topography of Pluto from New Horizons. Icarus, 314, pp.400-433. 


\section{Figures}

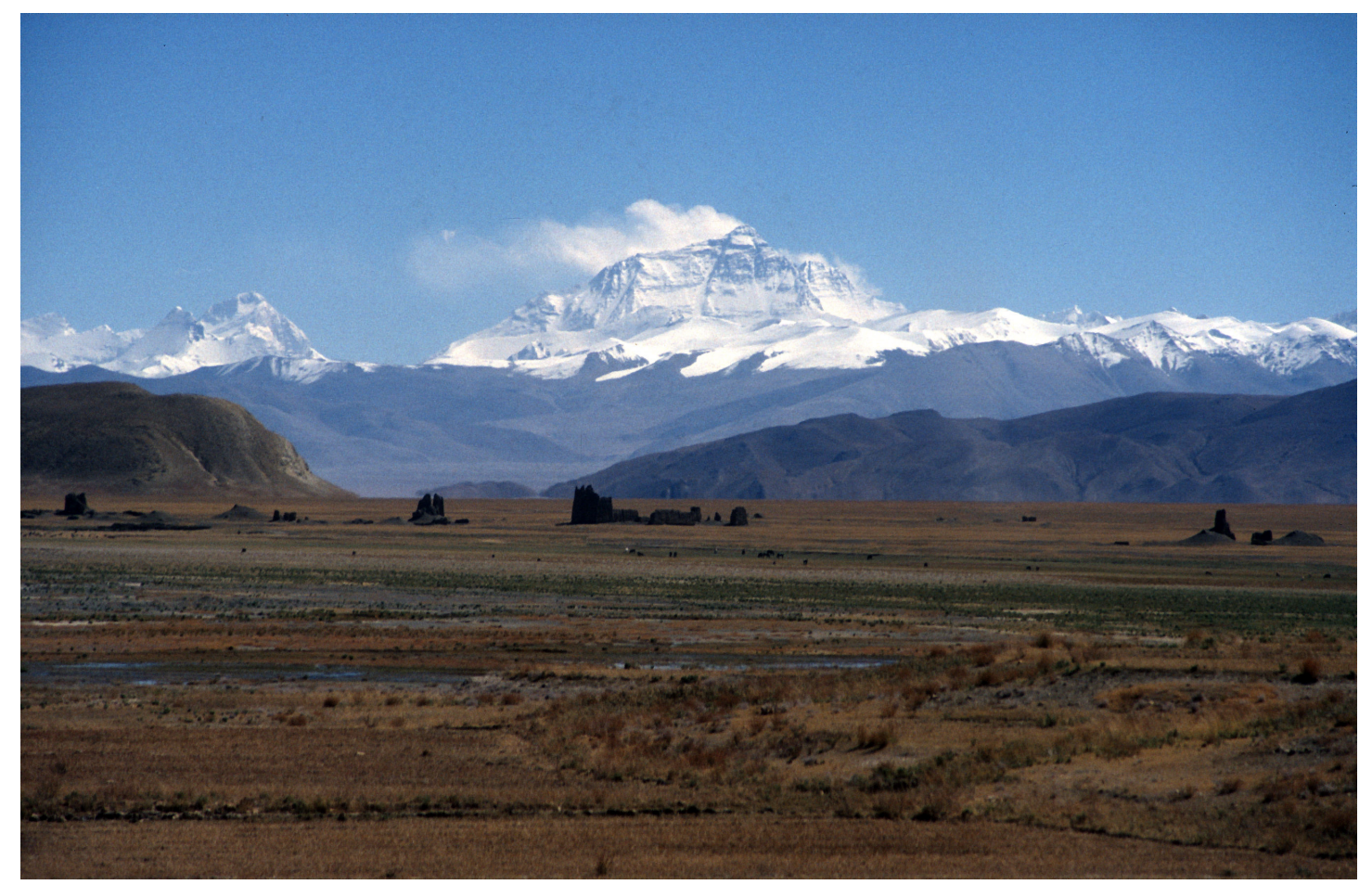

Figure 1 The north face of Mount Everest $(8,848 \mathrm{~m})$ viewed from the Tibet plateau.

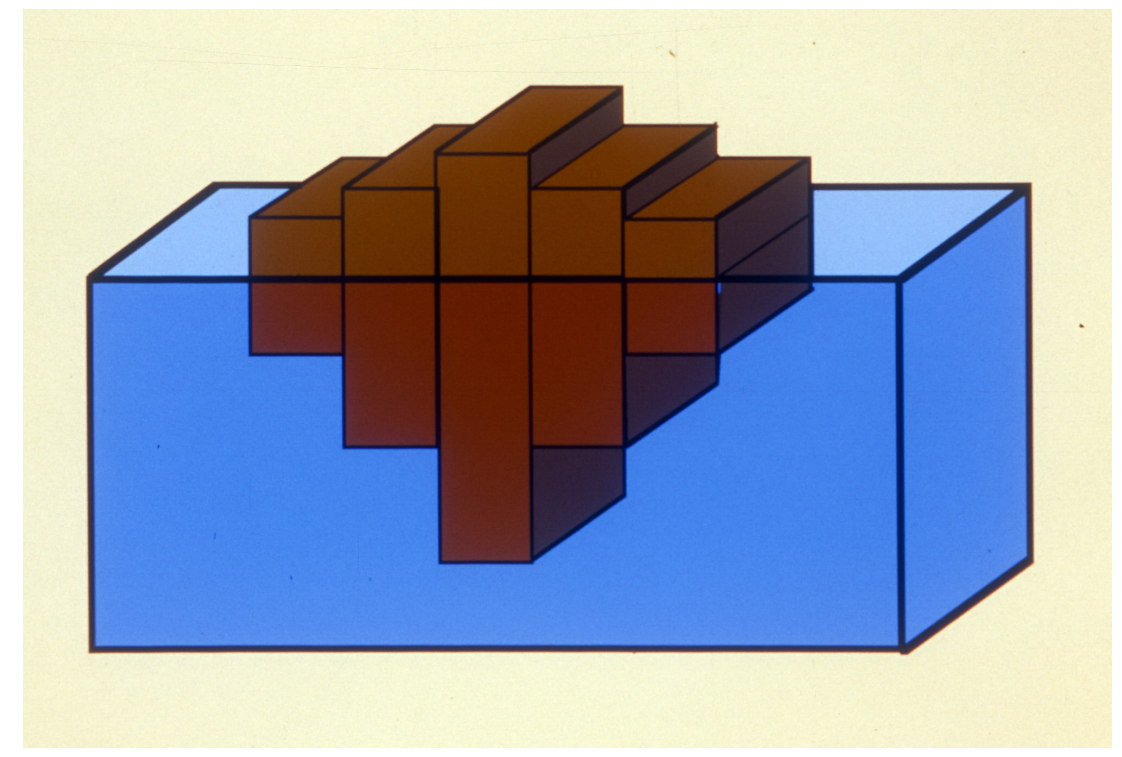

Figure 2 The principal of isostacy illustrated by the analogy of wooden blocks (representing the lithosphere) floating on water (representing the asthenosphere). The highest surface elevations are supported by deep 'roots' protruding into the water. Buoyancy provides the support. (Credit: Open University) 


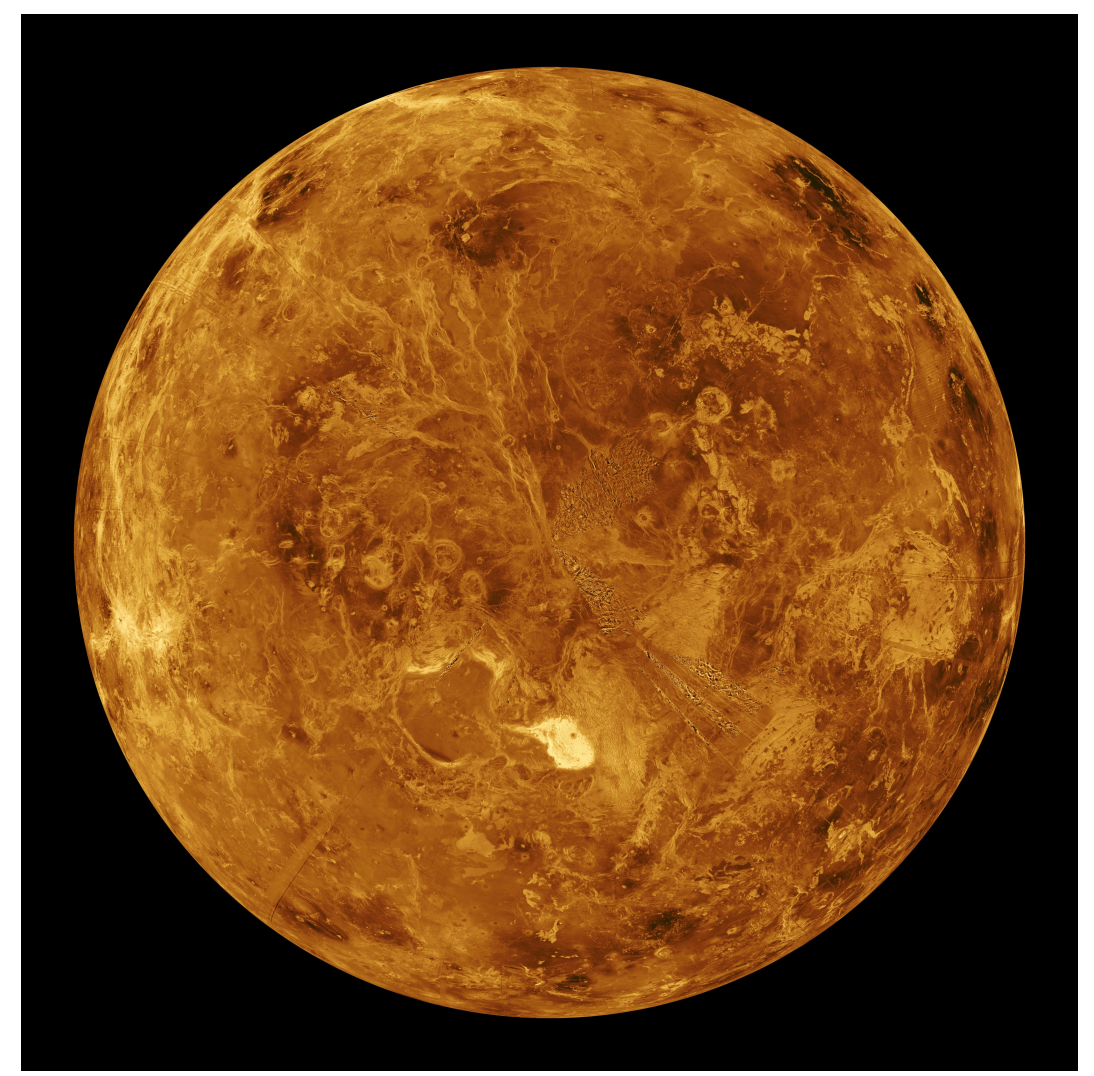

Figure 3 Venus, northern hemisphere, compiled from radar images. Maxwell Montes is seen as the white lens in the bottom half of the image. (Credit: NASA/JPL)

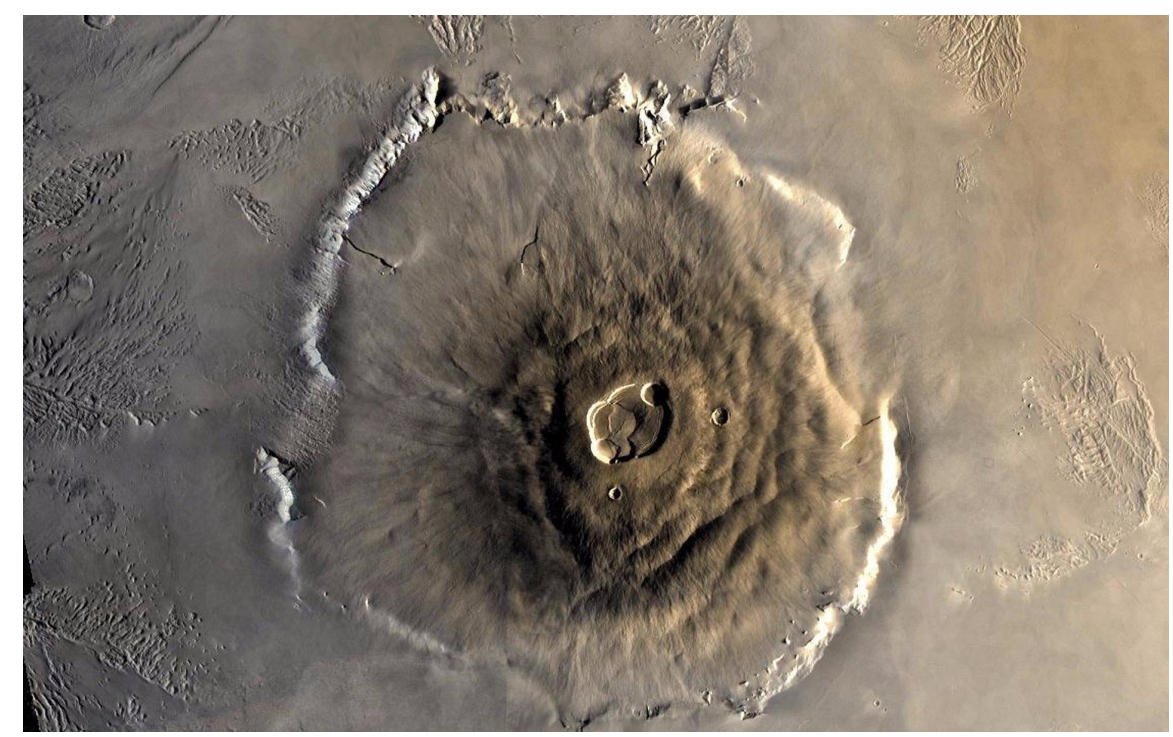

Figure 4 3D image of Mons Olympus (21,229 m), Mars, constructed from colour mosaic. Height of image $\sim 500 \mathrm{~km}$. Note the flexural moat formed around the perimeter of the structure. (Credit: NASA/JPL) 


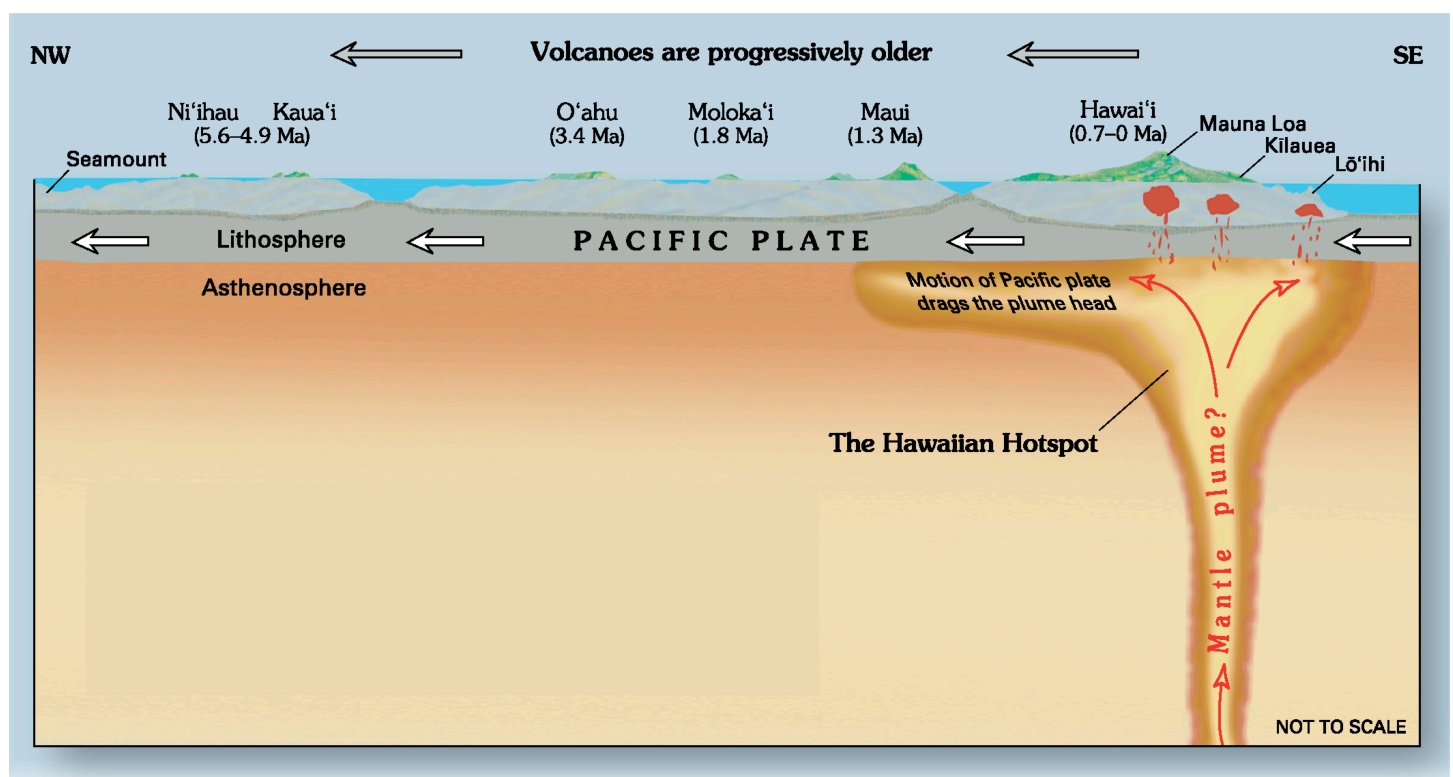

Figure 5 Cartoon of vertical section through the Hawai'i chain forming above the hotspot. (Credit: Joel E. Robinson, USGS)

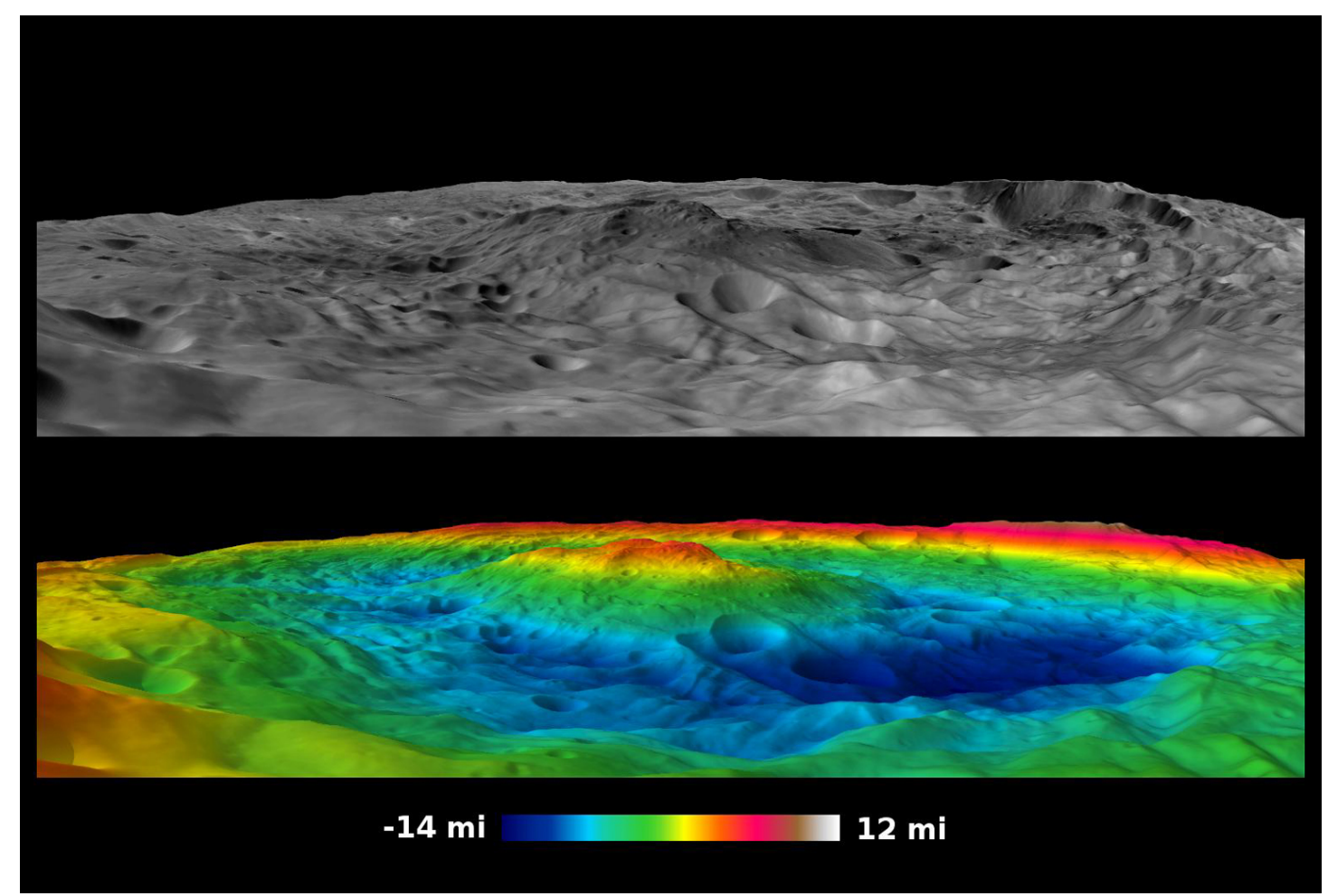

Figure 6 Radar image of south pole of Vesta across the Rheasilvia crater, measuring about $500 \mathrm{~km}$ across. Scale of false colour elevation model (below) ranges from depths of $20 \mathrm{~km}$ (deep blue) to heights of $20 \mathrm{~km}$ (white). (Credit: NASA/JPLCaltech) 


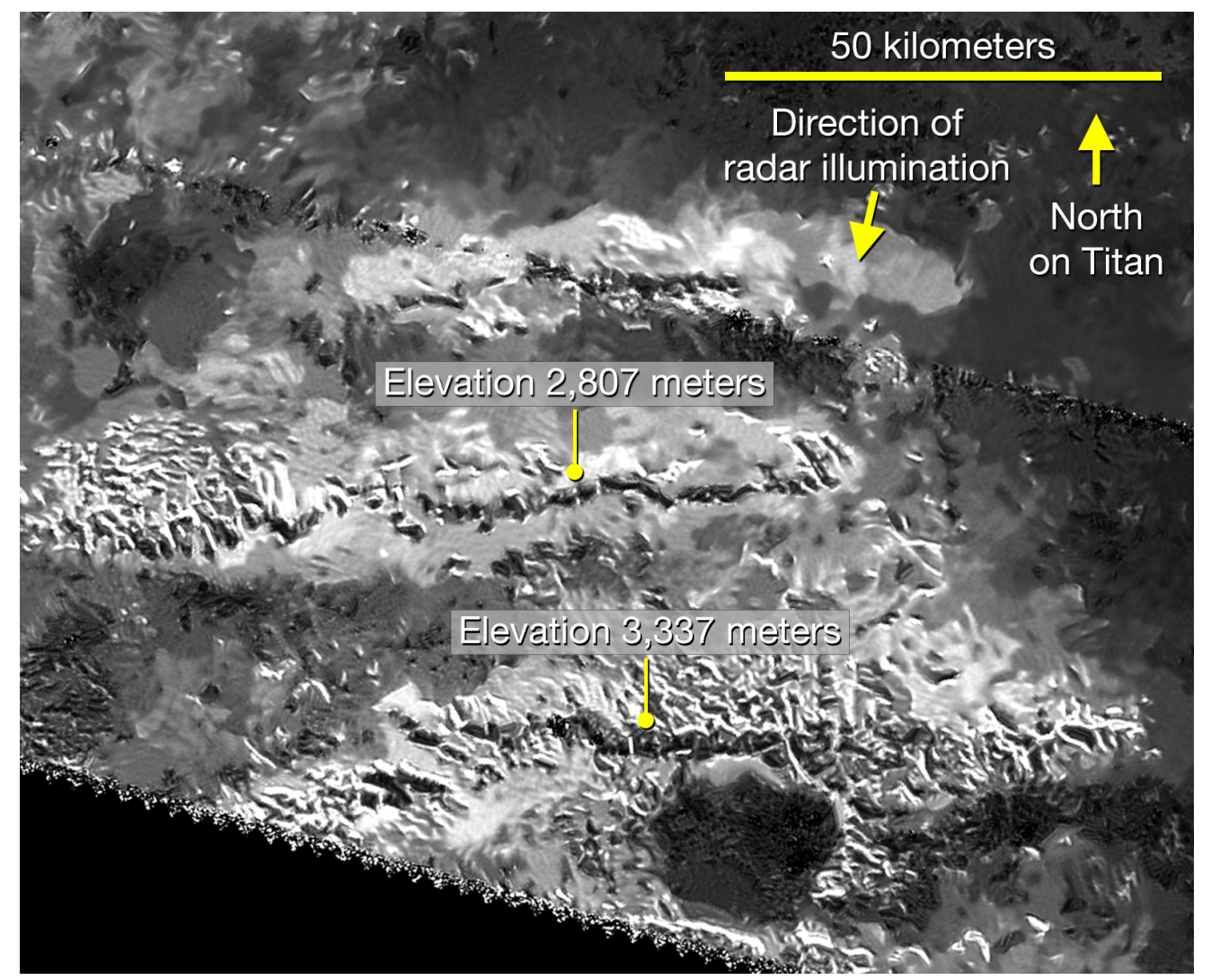

Figure 7 A radar image of Mithrim Montes on Titan. (Credit: NASA/JPL-

Caltech/ASI)

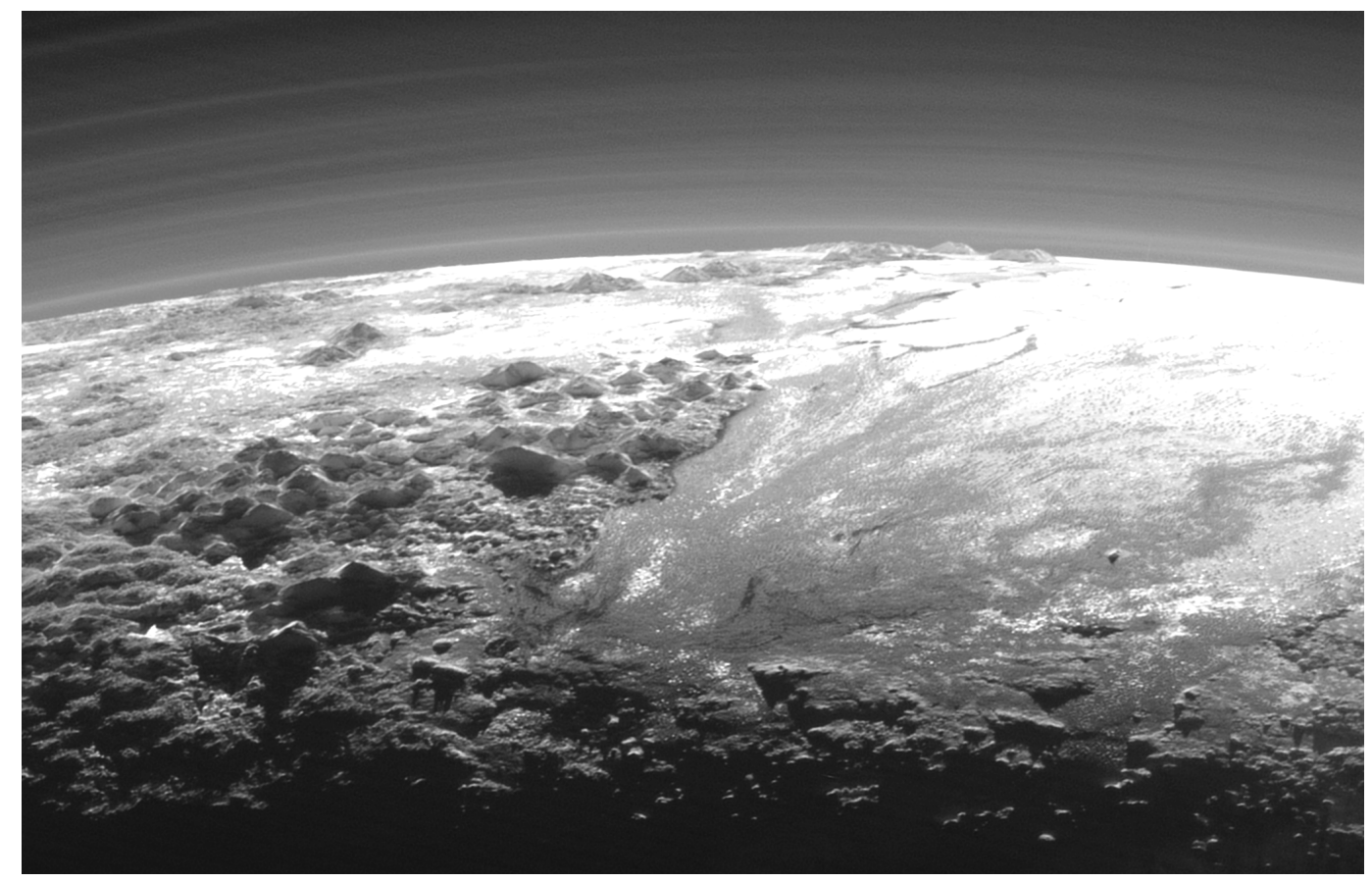

Figure 8 The highest mountains on Pluto: Tenzing Montes $(6,200 \mathrm{~m})$ in the foreground and Hillary Montes in the distance. Width of image is about $400 \mathrm{~km}$. (Credit: NASA/JHUAPL/SwRI) 


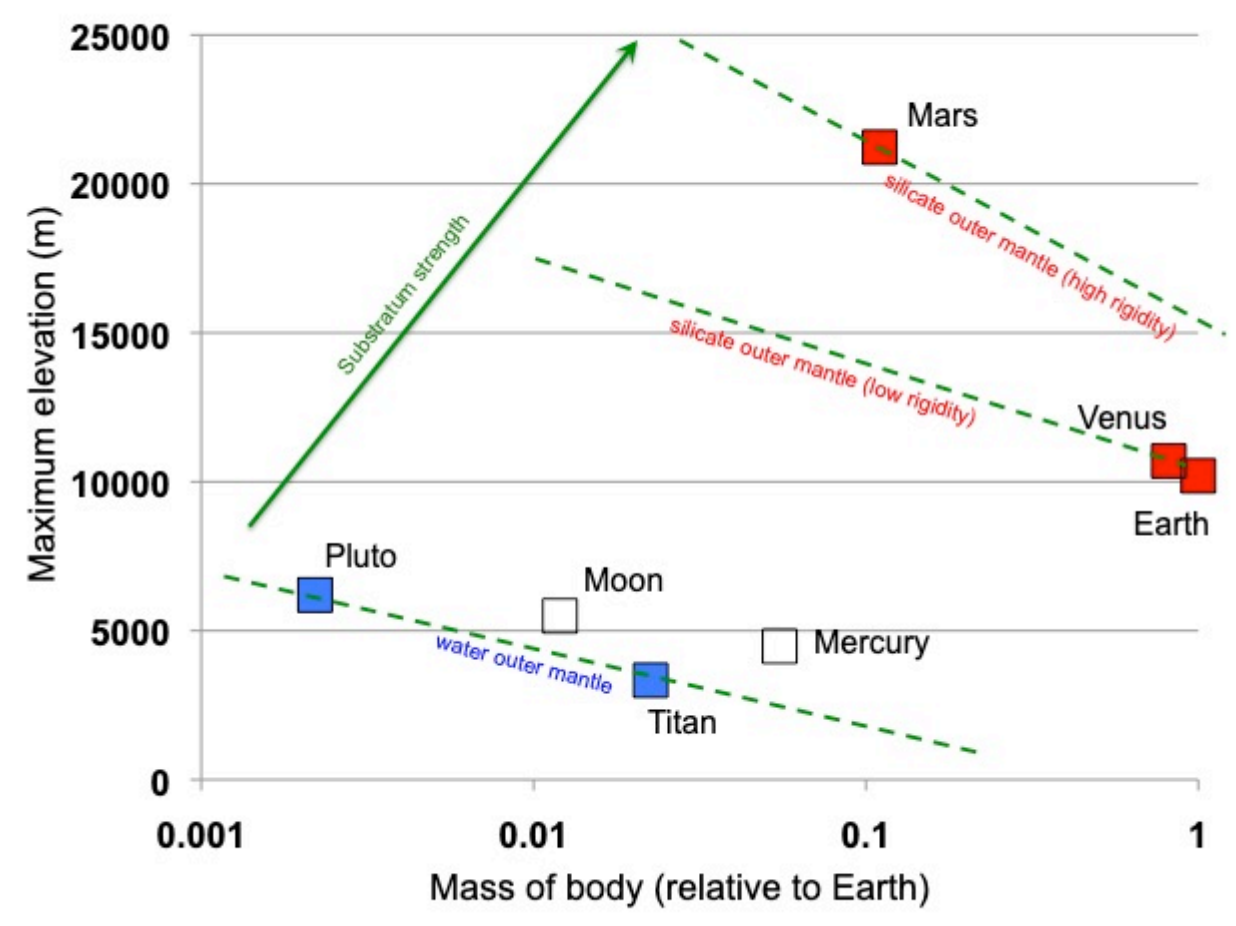

Figure 9 Diagram plotting the maximum elevation found on planetary bodies against planetary mass, with schematic isopleths for the relative strength of the outer mantle (dashed green lines). Red squares indicate planets with a silicate outer mantle; blue squares indicate bodies with water outer mantle. Note that this relationship can only apply where tectonism or magmatism is sufficient to achieve maximum possible altitudes. Where both tectonism and magmatism are relatively quiescent mountains of such high elevations will not be observed as seen on our moon and Mercury (open squares). 